\title{
Letšeng Diamond Mine, Lesotho: Recent Advances in the Open Pit Geology of the Satellite Kimberlite Pipe
}

\author{
Teboho Nkotsi ${ }^{1}$, Casey Hetman ${ }^{2}$, Jock Robey ${ }^{3}$, Barbara Scott Smith ${ }^{4}$ and Mohapi Mohapi ${ }^{1}$ \\ ${ }^{1}$ Letšeng Diamonds (Pty) Ltd., Letšeng-la-Terae, Lesotho,nkotsit@letseng.co.ls \\ ${ }^{2}$ SRK Consulting, Vancouver, BC, Canada, chetman@srk.com \\ ${ }^{3}$ Rockwise Consulting, Kimberley, South Africa, jjrobey@telkomsa.net \\ ${ }^{4}$ Scott-Smith Petrology Inc., North Vancouver, BC, Canada, barbara@scottsmithpetrology.com \\ ${ }^{1}$ Letšeng Diamonds (Pty) Ltd., Letšeng-la-Terae, Lesotho, mohapim@letseng.co.ls
}

Introduction

The Letšeng Diamond Mine in Lesotho differs from many other mines in southern Africa because it occurs near the margin of the Archaean Kaapvaal Craton, and produces some of the largest and most valuable diamonds from the lowest grade kimberlite mined in the world. The Mine comprises two adjacent steep-sided volcanic kimberlite pipes, Satellite and Main. In the Satellite pipe historic mapping of surface exposures, underground tunnels and drillcore logging during evaluation by Rio Tinto Exploration (1967-1972) reported nine poorly documented phases of kimberlite that were later combined into a single phase during limited mining by De Beers (1977-1982). Subsequently, Letšeng subdivided the pipe into two dominant kimberlite domains: Southern Volcaniclastic Kimberlite (SVK) and Northern Volcaniclastic Kimberlite (NVK). This investigation demonstrated more complex geology (Fig. 1) based on mapping of recent open pit exposures, logging of blast-hole and ahead of face drill chips and petrography. These results have been integrated with macrodiamond production data and drillcore information to update the present 3D geology model used for mine planning purposes.

\section{Pipe Geology}

The $~ 90$ Ma Satellite Pipe (Stanley et al. 2015) is a smooth, steep-sided pipe that has an oval surface expression of approximately 5.2 ha. The pipe was emplaced into $\sim 1800-2000 \mathrm{~m}$ thick sequence of Karoo basalts, which are partially exposed in the open pits. These basalts dominate the observed xenoliths within the kimberlite and range in size from microxenoliths to large-megaxenoliths with lengths greater than $100 \mathrm{~m}$ (Fig. 1). The majority of the pipe-fill is classified as Kimberley-type pyroclastic kimberlite (KPK; formerly tuffisitic kimberlite) broadly comparable to the type area pipes in Kimberley, South Africa (Scott Smith et al. 2013). Other textural types include hypabyssal kimberlite (HK) and rocks with textures transitional between HK and KPK.

\section{Internal Geology}

Distinct phases of kimberlite have been identified based on features including variations in kimberlite textures, size and abundance of country rock xenoliths and olivine macrocrysts, as well as the degree of xenolith-kimberlite reaction. This investigation of the current mining levels to $\sim 190 \mathrm{~m}$ below surface confirmed that pipe-fill is dominated by SVK and NVK and that they are separated by a steep, sharp cross-cutting internal contact. Internal complexities within the SVK and NVK domains have been established and in addition, two new smaller phases of kimberlite have been identified: the Central Volcaniclastic Kimberlite (CVK) and the Central Coherent Kimberlite (CCK) as shown in Figure 1. All the kimberlites in the Satellite Pipe are characterised by very low abundances of mantlederived xenocrysts (indicator minerals); however, garnet and spinel bearing peridotite xenoliths may be locally abundant within the NVK.

The dominant pipe-fill within the Satellite pipe is SVK, a uniform KPK with minor layering observed adjacent to the pipe wall and large xenoliths. It is a dark grey to green, altered kimberlite which contains 35 modal \% fine-medium grained pseudomorphed olivine. The SVK consists of clast 
supported, loosely packed cored and uncored magmaclasts and partly altered to fresh basalt xenoliths set within an altered

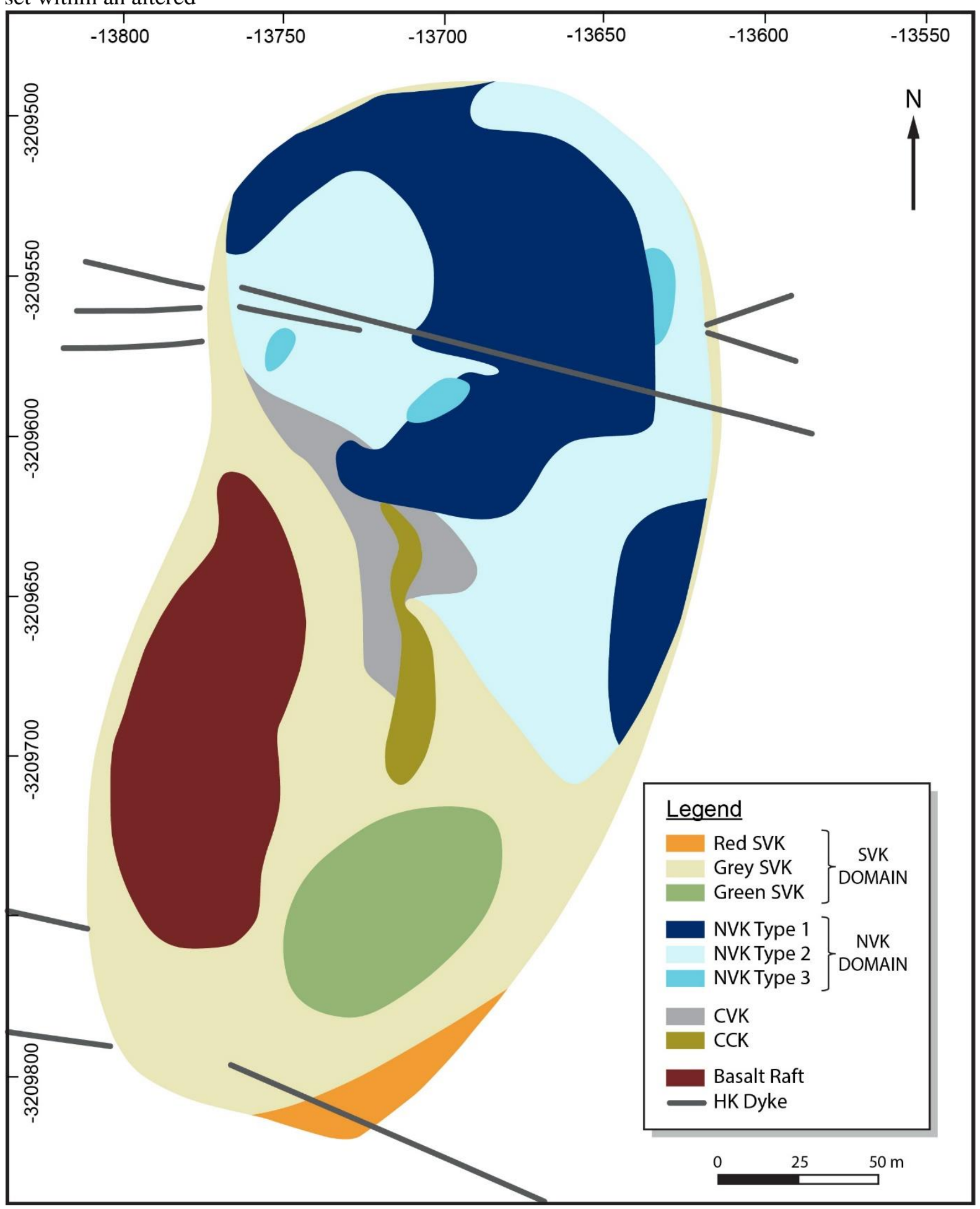

Figure 1: Plan view of the Satellite Pipe showing the internal geology between 3050-2878m above sea level.

interclast matrix. Primary groundmass minerals within the magmaclasts include variable amounts of melilite, phlogopite, spinel and perovskite. The mantle content of the SVK is uniform and three subtypes (green SVK, red SVK, grey SVK; Fig.1) have been mapped based on variations in country rock xenolith abundance and degree of reaction with the host kimberlite. 
The second volumetrically significant pipe infill is NVK which is notably inhomogeneous with three subtypes identified in pit exposures and subsurface drillcores. The subtypes display different textures ranging from KPK to HK. Other variations include the size and proportion of basalt xenoliths, the degree of xenolith to kimberlite reaction and the sizes of both the magmaclasts and olivine macrocrysts. Most of the NVK is altered, massive, dark grey to black KPK (Type 2) containing 40-45 modal $\%$ pseudomorphed olivine, abundant matrix-supported magmaclasts and common, extensively reacted basalt xenoliths. The magmaclasts are both cored and uncored with selvages containing phlogopite, melilite, spinel and perovskite. The other NVK subtypes include an HK with textures transitional to KPK (Type 1) characterized by a similar modal \% of olivine; however, this rock type contains conspicuous olivine macrocrysts larger than $1 \mathrm{~cm}$ as well as common magmaclasts larger than $5 \mathrm{~cm}$. Type 3 NVK is considered a minor rock type with $35-45$ modal \% pseudomorphed olivine and is characterized by distinct layering defined by basalt xenoliths.

The newly established phase of kimberlite termed CVK has been identified in the centre of the pipe close to the NVK/SVK contact. This kimberlite is similar to the SVK and distinctly different from the NVK. It is a grey, massive KPK which contains 30-40 modal \% fine to medium grained olivine macrocrysts that are much finer grained compared to both the SVK and NVK rock types.

The Central Coherent Kimberlite (CCK) is late-stage irregular HK intrusion which cross-cuts the SVK and CVK and ranges in thickness from a few centimetres up to 4-5 $\mathrm{m}$. The CCK is a dark brown, massive, homogenous, well crystallized HK containing abundant fresh olivine crystals (55 modal \%) characterised by complex morphology.

Several HK dykes are associated with the pipe which both predate pipe emplacement and cross-cut the pipe. The dykes are sub vertical, less than $1 \mathrm{~m}$ wide and range from perovskite and spinel-bearing phlogopite to carbonate kimberlites.

\section{Conclusions}

The emplacement history of the Satellite pipe can be reconstructed based on spatial relationships of the contrasting phases of kimberlite present within the pit exposures, together with the sharp, subvertical, cross-cutting relationships between them. The Satellite pipe was formed along and cross-cuts a pre-existing northeast-southwest kimberlite dyke system. The first of two major pipe forming events was the SVK. A number of thin remnants of SVK present between the NVK and the country rock indicates that the initial SVK event involved formation of the entire Satellite Pipe together with the relatively uniform KPK pipe-infill. This was followed by the emplacement of the NVK as a pipe which dominated the northern part of the Satellite pipe, and was nested within the SVK. The internally complex NVK includes KPK, HK and layered VK. The smaller CVK comprises a finer grained KPK emplaced along the boundary of the NVK and SVK domains. The CCK formed an irregular intrusion cross-cutting both the SVK and CVK. Finally, various cross-cutting HK dykes pass from the country rock into the Satellite pipe.

\section{References}

Scott Smith BH, Nowicki TE, Russell JK, Webb KJ, Mitchell RH, Hetman CM, Harder M, Skinner EMW and Robey JvA (2013) Kimberlite Terminology and Classification. Proceedings of 10th International Kimberlite Conference, Volume Two, Special Issue of the Journal of the Geological Society of India, Volume 2, 1-17. Springer India.

Stanley JR, Flowers RM, and Bell DR (2015) Erosion patterns and mantle sources of topographic change across the Southern African Plateau derived from the shallow and deep records of kimberlites, Geochem. Geophys. Geosyst., 16, doi:10.1002/. AGU Publications. 2015GC005969. 